\title{
Evaluation of Bosniak category IIF complex renal cysts
}

\author{
Ole Graumann • Susanne Sloth Osther • Jens Karstoft • \\ Arne Hørlyck • Palle Jörn Sloth Osther
}

Received: 6 December 2012 /Revised: 29 March 2013 / Accepted: 16 April 2013 /Published online: 15 May 2013

(C) The Author(s) 2013. This article is published with open access at Springerlink.com

\begin{abstract}
Purpose To evaluate moderately complex renal cysts of Bosniak category IIF.

Materials and methods The regional ethics committee approved the study. In the period 2003-2009, radiological CT reports of 8,402 CT examinations of the kidneys were analysed retrospectively by one radiologist. All complex cystic lesions in the kidney $(n=550$ in the same number of patients) were reclassified according to the Bosniak classification by two radiologists in consensus. If a patient had more than one lesion, only the highest Bosniak category was recorded. All Bosniak IIF lesions with $\geq 2$-year follow-up were included in the study.

Results Thirty-two Bosniak IIF lesions were found. Five lesions (16\%) were upgraded during follow-up and the patients were offered surgery. Pathology of three lesions showed papillary carcinoma, clear cell renal carcinoma and chronic
\end{abstract}

O. Graumann $(\varangle) \cdot$ S. S. Osther $\cdot$ P. J. S. Osther

Urological Research Center, Department of Urology, Fredericia

Hospital, Fredericia, and Institute of Regional Health Services

Research, University of Southern Denmark, Dronningensgade 97,

DK-7000 Fredericia, Denmark

e-mail: olegraumann@dadlnet.dk

S. S. Osther

e-mail: susanne.Sloth.Osther@slb.regionsyddanmark.dk

P. J. S. Osther

e-mail: Palle.Joern.Osther@slb.regionsyddanmark.dk

\section{J. Karstoft}

Department of Radiology, Odense University Hospital, Sdr.

Boulevard 29,

5000 Odense, Denmark

e-mail: jens.karstoft@ouh.regionsyddanmark.dk

\section{A. Hørlyck}

Department of Radiology, Aarhus University Hospital,

Brendstrupgårdsvej 100,

Skejby, Denmark

e-mail: arnehoer@rm.dk inflammation, respectively. Due to comorbidity the remaining two patients were followed with CT without intervention. Ten lesions ( $31 \%$ ) with follow-up periods $>5$ years had no further radiological changes and clinical follow-up was stopped.

Conclusion The use of Bosniak category IIF is clinically applicable, resulting in an overall surgical nephron-sparing approach to complex renal cysts.

Teaching Points

- The Bosniak classification is used to categorise complex renal cystic masses

- BIIF cysts behave mostly as benign lesions

- Radiological progression in complexity occurs in only $16 \%$ of cases

- BIIF category seems promising for clinical application, potentially avoiding unnecessary surgery

Keywords Kidney neoplasms · Renal cystic masses · Multidetector computed tomography

$\begin{array}{ll}\text { Abbreviations } \\ \text { HU } & \text { Hounsfield units } \\ \text { PACS } & \text { Picture-archiving communication system } \\ \text { DLP } & \text { Dose length product } \\ \mathrm{mSv} & \text { Millisievert } \\ \mathrm{mA} & \text { Milliampere }\end{array}$

\section{Introduction}

Many lesions in the kidney are discovered by coincidence because of increased use of modern imaging modalities such as ultrasonography (US), computerised tomography (CT) and magnetic resonance imaging (MRI) [1-3]. Renal cysts are rare in children $(0.1 \%$ $0.45 \%$ ) and common in adults, with approximately $50 \%$ of individuals over 50 years of age having renal cysts [2, 4]. Renal cysts are most often simple and 
asymptomatic. Distinguishing simple renal cysts from solid tumours in the kidney does not represent a diagnostic challenge. Complex renal cysts, on the other hand, are still a clinical problem $[2,5,6]$. The most important element in the diagnostic categorisation of complex renal cysts is to be able to differentiate between benign and possibly malignant lesions-in other words to identify (1) which lesions require surgical intervention, (2) which can be safely followed by imaging and (3) which are unequivocally benign and need no surgical intervention or imaging follow-up.

The Bosniak classification is a diagnostic system for the differentiation of cystic renal lesions in the kidney using CT. It was introduced in 1986 and has been updated several times, most recently in 2005 [5]. The classification system is based on several morphological changes in renal cysts: septa formation, wall thickening including nodal components, calcification in the wall and/or septa, hyperdense cystic content and contrast enhancement after intravenous contrast injection. The cystic lesions in the kidney are divided into four categories using CT. Bosniak category I and II lesions are predicted to be benign, category III potential malignant and IV predominantly malignant. Category IIF (BIIF) has subsequently been introduced for those cysts that cannot be clearly categorised as category II or III and therefore need follow-up imaging. Since 1993, when M.A. Bosniak added the category IIF, few studies have been published regarding this subject and only three series with more than ten BIIF lesions [6-13].

The aim of this study was to investigate the usefulness of Bosniak category IIF and evaluate the clinical outcome of moderately complex renal cysts compared to published data in the literature.

\section{Materials and methods}

The regional ethics committee approved the study, project ID: S-20090137. In a 7-year period (January 2003December 2009) radiological reports from 8,402 CT examinations of the kidney were analysed retrospectively by one radiologist with 5 years' experience. All patients with complex renal cysts and normal renal function (estimated creatinine clearance $>60 \mathrm{ml} / \mathrm{min} / 1.74 \mathrm{~m} 2$ ) diagnosed on multiphase contrast-enhanced $\mathrm{CT}$ and with $\geq 2$-year followup were included in the study $(n=550)$. The lesions on the CT examinations were reclassified according to the Bosniak classification by two experienced uroradiologists with 5 years and 20 years of experience, respectively. The image analysis was performed in consensus. All patients were recruited from one institution and were examined with the same follow-up protocol and with the same CT scanner and CT protocol. The complexity of each lesion was assessed according to the Bosniak classification on the basis of the number and appearance of the septa, wall thickness, hyperdense cystic content, interface with the kidney parenchyma, presence and amount of calcification, and contrast enhancement characteristics. Lesion size was measured in two dimensions on the axial image. Follow-up examinations were evaluated for any interval change. Estimated radiation exposure for each $\mathrm{CT}$ scan, represented in $\mathrm{mSv}$, was calculated with the conversion factor, $0.017 \mathrm{mSv} / \mathrm{mGy} \times \mathrm{cm} \times$ the dose length product (DLP).

In this study only Bosniak category IIF cysts were included. From the total number of BIIF lesions we selected patients with $\geq 2$ years of follow-up. This group was divided into (1) stable BIIF lesions with follow-up of 2-5 years, (2) stable BIIF lesions with follow-up of $\geq 5$ years and (3) those BIIF lesions that progressed in complexity and therefore

Fig. 1 Flowchart

8402 CT scans of the kidney<smiles>C1CCCC1</smiles>

1984 patients with renal cysts

Bosniak l excluded

550 complex renal cysts

Bosniak II, III and IV excluded

44 patients with Bosniak IIF

No follow up (n=6)

38 patients with Bosniak IIF

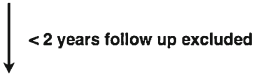

32 patients with Bosniak IIF $\geq 2$ years follow up
10 lesions with follow-up $\geq 5$ years were stable, suggesting benignity and follow-up imaging stopped

Clear cell renal carcinoma $(n=1)$

Papillary renal carcinoma $(n=1)$

Chronic inflammation $(n=1)$

Continued watchful waiting $(n=2)$

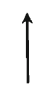

Five lesions progressed radiologically during follow up 

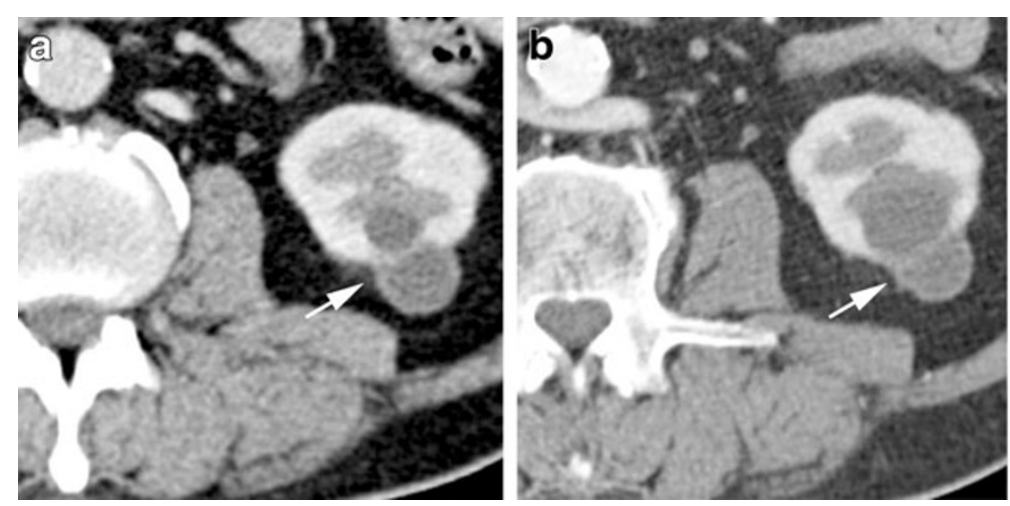

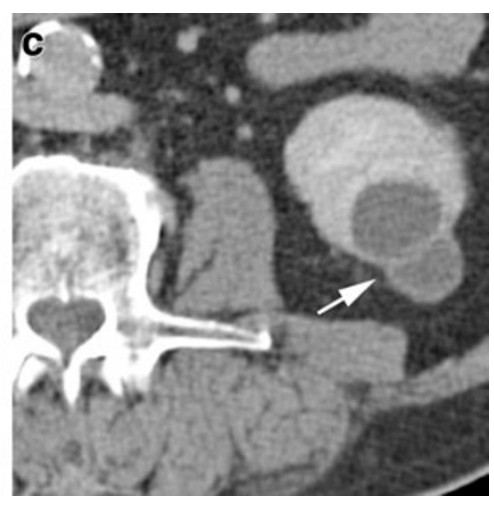

c nephrographic phase CT images after 4-year follow-up: The lesion progressed in complexity with enlargement of the intrarenal component leading to up-classification to BIII. Pathological diagnosis was clear cell renal carcinoma, primarily located focally in the septum

$320 \mathrm{mg} / \mathrm{ml}$, Iodixanol, GE Healthcare) was injected intravenously followed by a $20 \mathrm{ml}$ saline solution $(0.9 \% \mathrm{NaCl})$ flush with an injection rate of $4 \mathrm{ml} / \mathrm{s}$. To obtain correct and reproducible contrast phases, the arterial contrast concentration was monitored with the region of interest (ROI) in the abdominal aorta at diaphragm level with a trigger level at 100 Hounsfield units (HU). Corticomedullary and nephrographic phase images were performed 10 and $65 \mathrm{~s}$ after the trigger. Scanning parameters were kept the same: $2.5 \mathrm{~mm}$ collimation $\times 4$; table speed $12.5 \mathrm{~mm} / \mathrm{s}$ (pitch, $1.25 \mathrm{~mm}$ ); $165 \mathrm{mAs} ; 120 \mathrm{kV} ; 512 \times 512$ matrix. All images were reconstructed with a soft algorithm and WW/WL at 400/40 in transversal, coronal and sagittal orientation in 3-mm slice thickness with an overlap of $2 \mathrm{~mm}$.

\section{Results}

The flowchart (Fig. 1) shows that of 550 complex renal cysts $\geq$ Bosniak category II, 44 patients had moderately
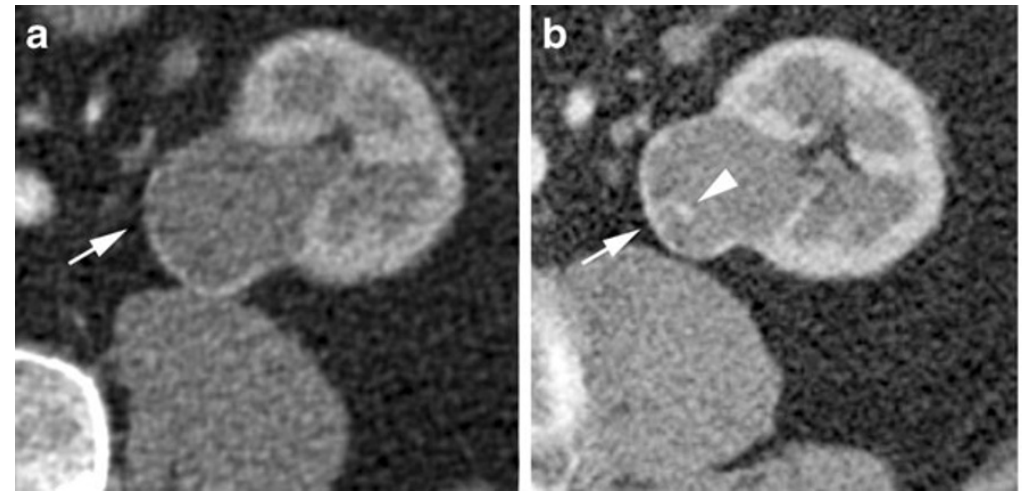

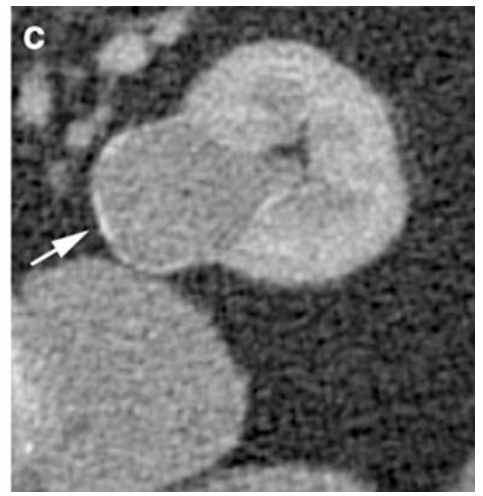

Fig. 3 Transversal baseline a corticomedullary phase CT image of a 61-year-old male with a moderately complex renal cystic lesion showing minimal thickening and calcification of the wall without enhancement (arrow), interpreted as BIIF. After 2-year follow-up the lesion progressed in complexity with a more irregular wall and was up- classified to BIII. Transversal b corticomedullary phase and $\mathbf{c}$ nephrographic phase images showing slightly thickened, partially calcified wall without measurable contrast enhancement (arrowhead) after the lesion had been up-classified. Pathologic diagnosis was papillary renal cell carcinoma 


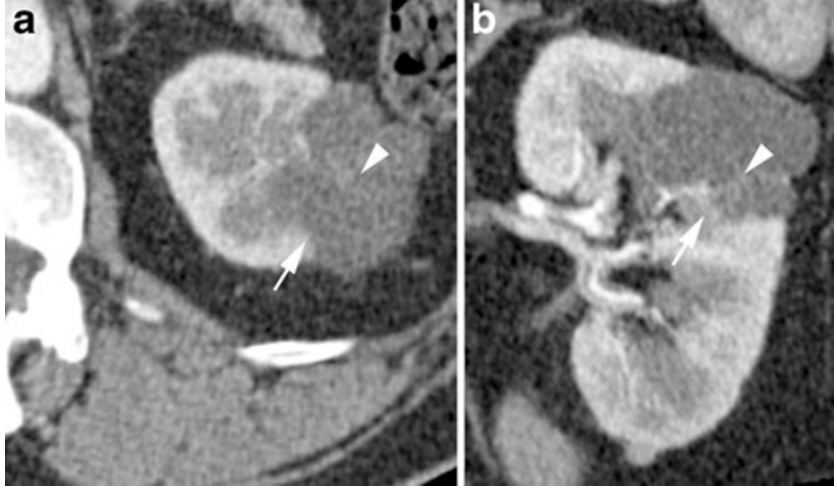

Fig. 4 Corticomedullary phase CT images in a transversal plane and $\mathbf{b}$ coronal plane of a 68 -year-old male with a moderately complex renal cystic lesion (arrow) showing hairline-thin smooth septa and wall with minimal thickening and calcification of septa without measurable contrast enhancement (arrowhead). There was no progression of the lesion after 5-year follow-up

complex renal cysts categorised as Bosniak IIF. For those BIIF lesions with a follow-up period $\geq 2$ years $(n=32)$, the mean follow-up was 1,393 days (735-4,046 days). Sixteen per cent (5/32) were upgraded to category BIII within a mean follow-up period of 3 years (735-1,539 days). Six patients had no follow-up CT and were excluded: two patients died from other disease, two patients had severe comorbidity, one patient did not wish to participate in the follow-up programme, and one patient, 14 years of age, was lost to follow-up. Mean radiation dose was $12.8 \mathrm{mSv}$ (7$30 \mathrm{mSv}$ ).

In the five patients who were upgraded, three underwent surgery, and the pathology of these three lesions showed papillary carcinoma, clear cell renal carcinoma (Figs. 2 and 3 ) and chronic inflammation with no malignancy, respectively. Due to comorbidity, the other two patients were not treated surgically; however at $\mathrm{CT}$ follow-up they did not show any further progression. Thirty-one per cent (10/32) of the lesions with mean follow-up periods $>5$ years (mean 1923 days, range 1229-4046 days) were stable during follow-up, suggesting benignity (Fig. 4). Table 1 presents a detailed summery of the cohort. Figures 5, 6, 7, 8, 9 and 10 show four different BIIF lesions from the cohort and examples of BII and BIII cysts.

\section{Discussion}

Classification and treatment of complex renal cysts represent a clinical challenge, demanding close cooperation between urologists and uroradiologists. Bosniak revised the original classification system of renal cysts in 1993 to include a subset of category II lesions, category IIF cysts $[5,6$, 14]. This category represents more complex cystic lesions, which cannot unequivocally be classified as category II or III. According to Bosniak, these cysts are potentially malignant

Table 1 Summary of the cohort

\begin{tabular}{|c|c|c|c|c|c|}
\hline & Total & $\begin{array}{l}\text { BIIF } \\
\text { Follow-up } \\
\geq 2 \text { years }\end{array}$ & $\begin{array}{l}\text { BIIF } \\
\text { Follow-up 2- } \\
5 \text { years }\end{array}$ & $\begin{array}{l}\text { BIIF } \\
\text { Follow-up } \\
>5 \text { years }\end{array}$ & $\begin{array}{l}\text { BIII } \\
\text { BIIF upgraded during } \\
\text { follow-up }\end{array}$ \\
\hline Number of lesions with follow-up $\geq 2$ years & 44 & 32 & 17 & 10 & 5 \\
\hline Sex (male/female) & $26 / 18$ & $17 / 15$ & $8 / 9$ & $5 / 5$ & $4 / 1$ \\
\hline Mean age in years & 66.64 & 65.31 & 64.59 & 66.10 & 66.20 \\
\hline (Range) & $(14-87)$ & $(40-87)$ & $(40-87)$ & $(46-83)$ & $(61-80)$ \\
\hline Mean follow-up time in days & 962 & 1,393 & 1,164 & 1,923 & 1,113 \\
\hline (Range) & $(0-4,046)$ & $(735-4,046)$ & $(760-1,956)$ & $(1,229-4,046)$ & $(735-1,539)$ \\
\hline Mean lesion size in $\mathrm{mm} \mathrm{A} \times \mathrm{B}^{*}$ & $37 \times 30$ & $37 \times 30$ & $39 \times 33$ & $34 \times 27$ & $36 \times 28$ \\
\hline (Range) & $\begin{array}{r}(6-98) \times \\
(6-81)\end{array}$ & $\begin{array}{c}(13-77) \times \\
(8-73)\end{array}$ & $\begin{array}{r}(13-77) \times \\
(10-73)\end{array}$ & $\begin{array}{c}(13-77) \times \\
(8-63)\end{array}$ & $(17-75) \times(11-60)$ \\
\hline $\begin{array}{l}\text { Lesion changes in size } \\
\text { Stable/increase/decrease }\end{array}$ & $36 / 8 / 0$ & $24 / 8 / 0$ & $12 / 5 / 0$ & $9 / 1 / 0$ & $3 / 2 / 0$ \\
\hline Number of septa $(0 /<5 / 5-9 />9)$ & $30 / 9 / 2 / 3$ & $19 / 8 / 2 / 3$ & $10 / 5 / 0 / 2$ & $7 / 1 / / 2 / 0$ & $2 / 2 / 0 / 1$ \\
\hline Septal appearance (none/thin/thickened) & $30 / 5 / 9$ & $19 / 5 / 8$ & $10 / 2 / 5$ & $7 / 2 / 1$ & $2 / 1 / 2$ \\
\hline $\begin{array}{l}\text { Calcification (None/minimal/mild/moderate/ } \\
\text { massive) }\end{array}$ & $21 / 4 / 10 / 9 / 0$ & $12 / 4 / 8 / 8 / 0$ & $6 / 1 / 6 / 4 / 0$ & $3 / 3 / 1 / 3 / 0$ & $3 / 0 / 1 / 1 / 0$ \\
\hline $\begin{array}{l}\text { Lesion interface with kidney parenchyma } \\
\text { (sharp/indistinct) }\end{array}$ & $42 / 2$ & $30 / 2$ & $17 / 0$ & $10 / 0$ & $3 / 2$ \\
\hline $\begin{array}{l}\text { Contrast enhancement (none/enhancement/ } \\
\text { maybe) }\end{array}$ & $36 / 0 / 8$ & $24 / 0 / 8$ & $15 / 0 / 2$ & $8 / 0 / 2$ & $1 / 0 / 4$ \\
\hline
\end{tabular}

*Lesion size was measured in two dimensions on the axial image 

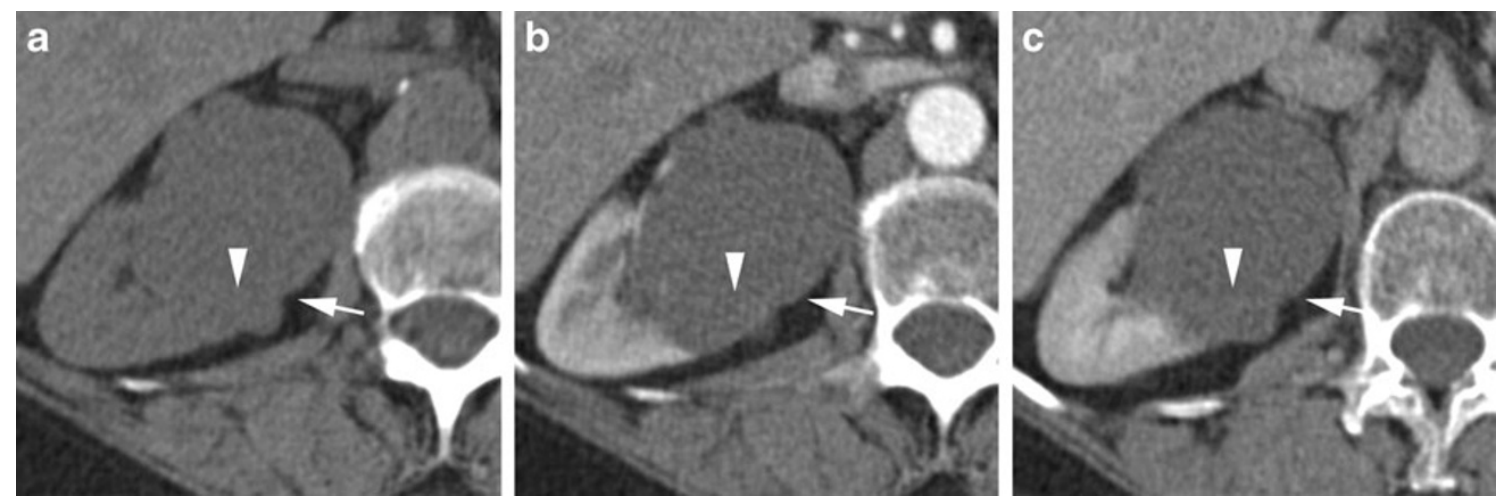

Fig. 5 Transversal a non-contrast, b corticomedullary phase and c nephrographic phase CT image of a 66-year-old female with a moderately complex renal cystic lesion (arrow) showing few septa without measurable contrast enhancement (arrowhead), interpreted as BIIF. During the last 3-year follow-up, the lesion progressed in size but not in complexity. Note the small hemangioma in the liver and should be followed with CT examinations, performed to determine whether the cystic lesions change over time with regard to morphology and contrast enhancement pattern, subsequently resulting in an up- or downgrading $[6,9,15,16]$. Category IIF moderately complex renal cysts may contain increased numbers of thin septa or a slightly thickened but smooth septum/septa or wall. They may also contain calcifications that may be thick and nodular, but without contrastenhancing elements. Completely intrarenal high-attenuation cysts $\geq 3 \mathrm{~cm}$ also belong to this group.

Cystic lesions in the kidney may have a variety of different aetiologies [2]. Most malignant complex renal cysts are cystic renal cell carcinomas (CRCC). Like the multilocular cystic renal cell carcinoma (MCRCC), CRCC has a very good prognosis. They are slow growing and have a low metastatic potential $[7,17-20]$. Due to benign changes with solid components like in mixed epithelial and stromal tumours (MEST), there will always be some benign lesions among the categories BIIF and above. These lesions are very rare, however [21]. Therefore, nephron-sparing surgery is proposed when MCRCC is suspected by preoperative radiologic criteria.

The Bosniak classification consists of a number of different entities including septa characteristics and enhancement, potentially resulting in differences of interpretation among readers [1-3]. In order to validate the classification system further, studies regarding intra- and interobserver variation after the introduction of the updated version of the Bosniak classification are warranted. The best results are probably seen when radiologists are categorising complex renal cysts in plenum, as in our study $[1,2,4,12,22]$.

\section{Bosniak classification and clinical outcome}

Moderately and more complex renal cysts of category BIIF and above are quite rare, and consequently data with corresponding pathological findings are sparse. When BIIF lesions progress in terms of enhancement, changes in internal architecture by developing irregular, thick enhancing septa,
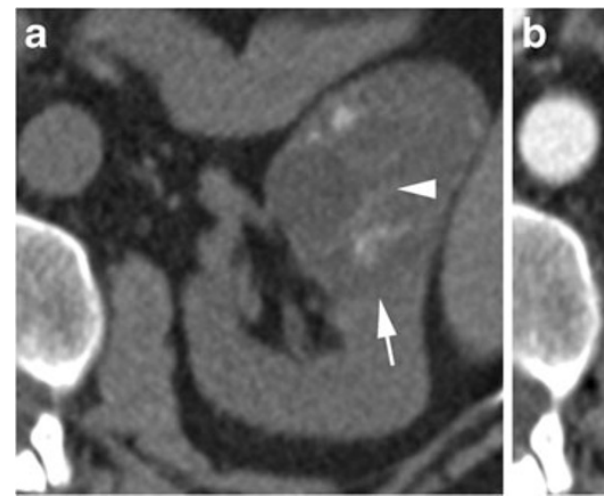

Fig 6 Transversal a non-contrast, $\mathbf{b}$ corticomedullary phase and $\mathbf{c}$ nephrographic phase CT image of a 70-year-old female with an indeterminate complex renal cystic mass (arrow) showing multiple septa with calcification and a suspicious nodular area without measurable contrast enhancement. The arrowheads show one example of such a suspicious area. The lesion was interpreted as BIIF but very close to a BIII and has been stable for the first 2 years of follow-up 

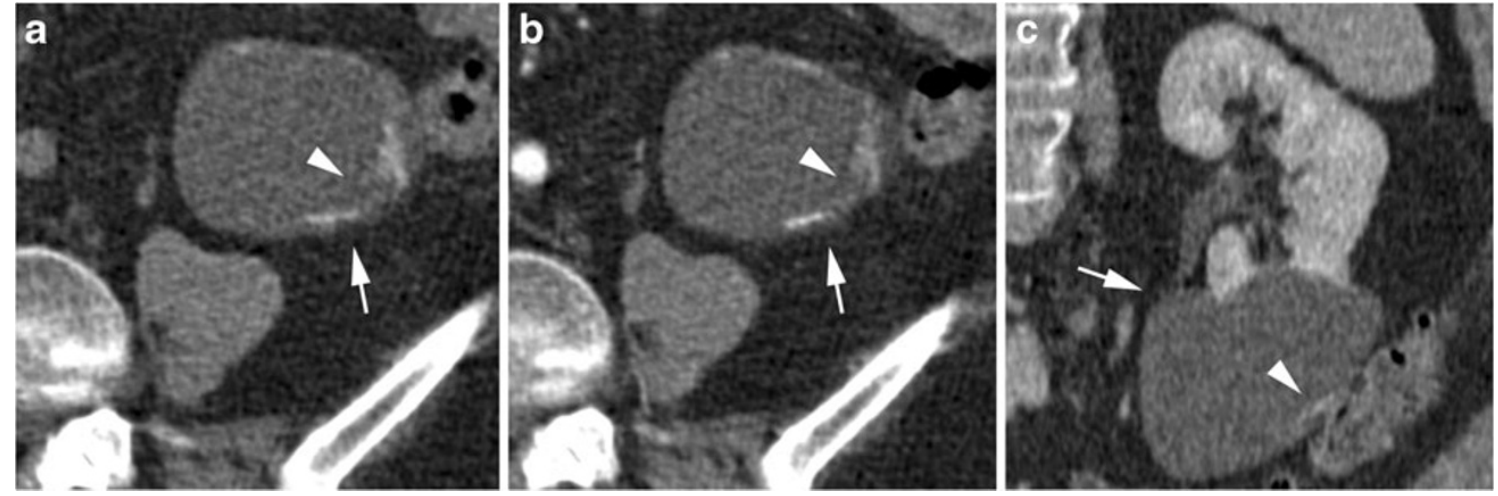

Fig 7 Transversal a non-contrast, $\mathbf{b}$ corticomedullary phase and $\mathbf{c}$ coronal nephrographic phase CT image of a 69-year-old female with a moderately complex renal cystic mass (arrow) showing the wall and

solid components or multilocular characteristics, they are upgraded, and interventions are recommended. Published series with more than 20 complex renal cysts with pathological findings are presented in Table 2. In the BIIF group, the $12 \%$ malignancy rate represents BIIF lesions with radiological progression in complexity over time and subsequent upgrading. Compared to the distribution of malignancy in each Bosniak category in publications before the introduction of BIIF, the accuracy of predicting malignancy in BIII lesions has improved from $51 \%$ to $61 \%$ after the introduction of BIIF, which means that by introducing this category approximately $10 \%$ could be spared surgical intervention. Surprisingly, the malignancy rate in the BII category is still unacceptably high (12\%), even in the series published after the introduction of BIIF.

We found 44 BIIF moderately complex renal cysts among 8,402 CT examinations of the kidneys in a 7-year period. During the follow-up $16 \%(5 / 32)$ of the lesions progressed radiologically, which corresponds well with the literature (Table 2). Unfortunately, we do not have histological specimens of all five BIIF lesions that progressed some septa containing thick and nodular calcification (arrowhead). The lesion was interpreted as BIIF; no progression was seen after 4 years of follow-up

radiologically because of co-morbidity of the patients. Two of three BIIF lesions with proven histology were malignant, indicating that radiological progression is indicative of malignancy. On the other hand, the two patients for whom histology was not available did not progress further radiologically during a mean follow-up of more than 3 years, suggesting that these lesions are either benign or low-grade aggressive.

\section{Imaging}

Several studies report that the chance of malignancy increases to $40-80 \%$ when enhancement is observed within a renal cystic lesion $[5,10,12,17,23]$. It is therefore of upmost importance that categorisation of complex cystic changes in the kidney is performed with high-quality CT in several phases. To detect enhancement in small areas such as a septum or the wall of a cyst, one cannot rely on split bolus CT examinations that present both corticomedullary and excretory phases in one examination. RCCs are often
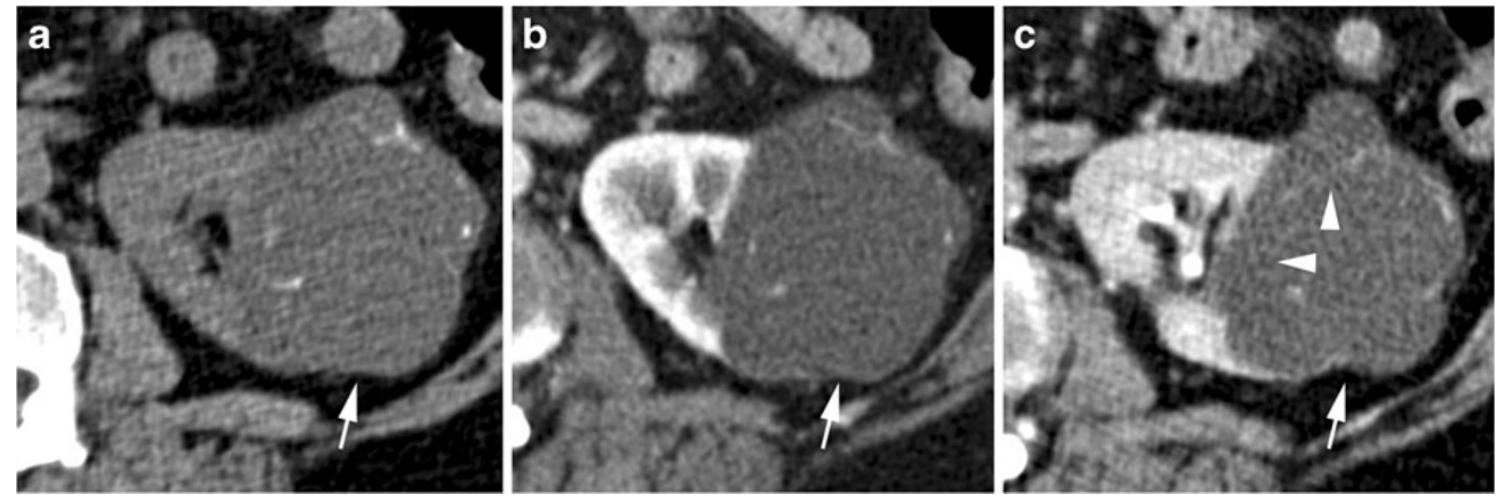

Fig. 8 Baseline transversal a non-contrast, b corticomedullary phase and $\mathbf{c}$ nephrographic phase CT image of a 64-year-old female with an indeterminate complex renal cystic mass (arrow) showing multiple septa with calcification and some slightly thickened septa with perceived enhancement (arrowhead). The lesion was interpreted as BIIF and has been stable for the first 3 years with MRI follow-up (not shown) 

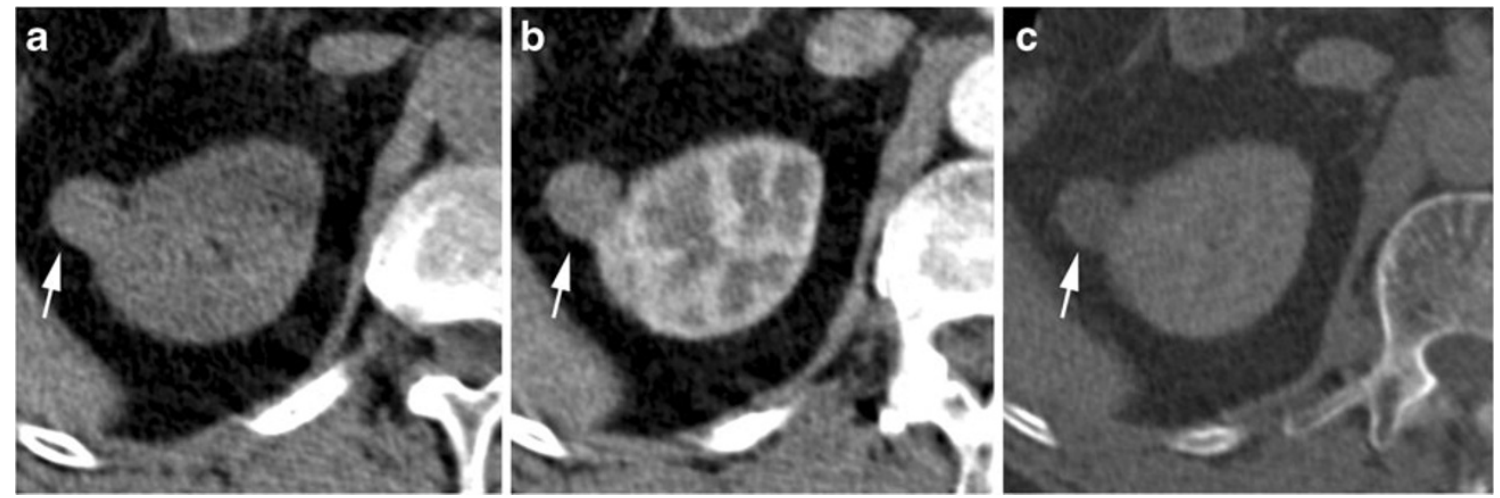

Fig 9 Transversal a non-contrast, b corticomedullary phase and $\mathbf{c}$ nephrographic phase CT image of a 85-year-old male with a typical benign BII exofytic hyperdense cyst (arrow) measuring $35 \mathrm{HU}$ in all phases

hypervascular and therefore have a characteristic contrast enhancement pattern characterised by washout in the venous phase [33]. Usually protocols for characterising complex renal cysts consist of a $\mathrm{CT}$ without contrast (non-contrast CT, NCCT) and a minimum of two CT single-bolus phases with contrast-enhanced $\mathrm{CT}$ and CCT in an arterial and venous phase, respectively $[2,5]$. Most radiologists would agree that pre- and post-contrast CT examinations are mandatory, but the number of post-contrast phases is debatable.

In most centres a multidetector CT (MDCT) is available with the possibility of performing isotropic multiplanar reconstruction in high quality. Technically, there are different software opportunities for CT-including software algorithms - to help assess iodine content in a lesion or dual-energy modes to gain additional/alternative information regarding complex renal cystic masses. Preliminary data are available in the literature regarding these issues $[34,35]$ but further studies are needed.

It is estimated that the risk of getting a fatal cancer from the ionised radiation of CT scans is approximately $1 / 1,000$ for every $10 \mathrm{mSv}$ received, assuming an effective dose of $10 \mathrm{mSv}$ per scan and a risk of $5 \%$ per Sievert [36]. One study suggests that $2 \%$ of all future cancers may be due to radiation exposure from CT examinations [37]. This statement has been widely criticised and the numbers are probably lower [38, 39]. Depending on patient size and body habitus, radiation doses from CT are often quite high - in the range of and even above 20-30 mSv in case of 64-channel CT scanners. In our study the mean radiation dose was $12.8 \mathrm{mSv}(7-30 \mathrm{mSv})$ on our four-channel CT. It is very important to perform radiological imaging according to the ALARA principle. This means that patients, regardless of age and disease, should be examined selectively with radiation doses "as low as reasonably achievably" according to the clinical problem in question. The Bosniak classification was initially developed solely on the basis of CT findings [1, 2]. Subsequently, a few studies have suggested that MR $[31,40]$ and CEUS $[4,8,41-46]$ may be equally useful for characterisation of complex renal cystic masses. Results from these studies are promising. However, both MR [31] and CEUS [8, 45, 46] have a tendency to
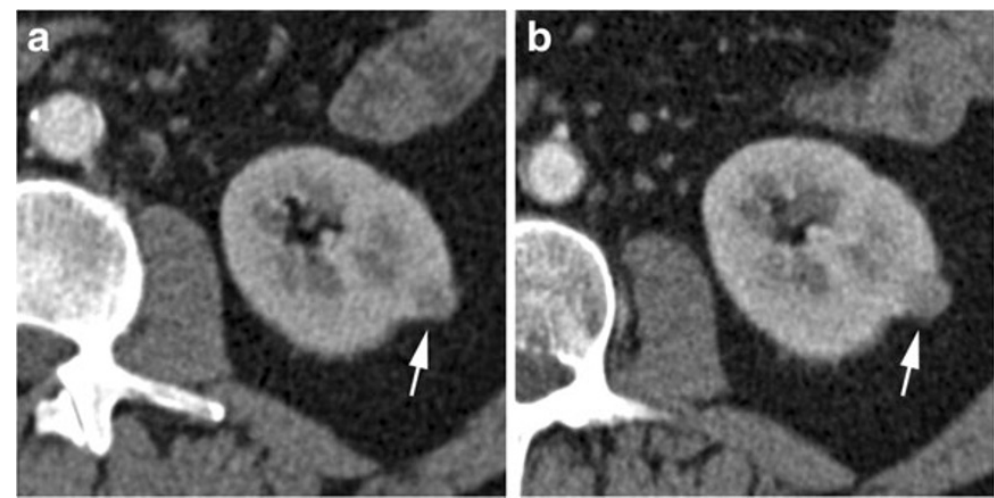

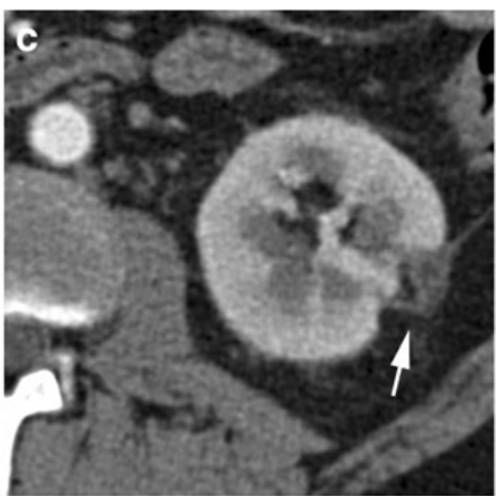

images of (a) baseline and (b) 3 month after right-sided nephrectomy. The BIII lesion (arrow) is almost solid after 3 months, indicating aggressive behaviour. No progression was seen at 6-month follow-up imaging after percutaneous cryoablation (c)
Fig 10 CT images of an 85-year-old male with a large renal cell tumour on the right side (not shown) and a left-sided indeterminate complex renal cyst with thickened enhancing wall, categorised as BIII. The patient underwent right-sided nephrectomy and percutaneous cryoablation on the left side. Transversal corticomedullary phase CT 
Table 2 Published series with more than 20 complex renal cysts with pathological findings

\begin{tabular}{|c|c|c|c|c|c|c|c|}
\hline References & Modality & $\mathrm{BI}$ & BII & BIIF & BIII & BIV & Total \\
\hline \multicolumn{8}{|l|}{ Before introduction of BIIF } \\
\hline Brown et al. (1989) [23] & $\mathrm{CT}$ & $0 / 2$ & $0 / 4$ & - & $3 / 12$ & $4 / 6$ & 24 \\
\hline Aronson et al. (1991) [24] & CT & - & $0 / 4$ & - & $5 / 9$ & $7 / 7$ & 20 \\
\hline Wilson et al. (1996) [25] & $\mathrm{CT}$ & $0 / 7$ & $4 / 5$ & - & $4 / 4$ & $6 / 6$ & 22 \\
\hline Cloix et al. (1996) [17] & CT & $1 / 2$ & $1 / 7$ & - & $4 / 13$ & $7 / 10$ & 32 \\
\hline Siegel et al. (1997) [3] & CT & $0 / 22$ & $1 / 8$ & - & $5 / 11$ & $26 / 29$ & 70 \\
\hline Bielsa et al. (1999) [26] & CT & - & $1 / 8$ & - & $7 / 9$ & $3 / 3$ & 20 \\
\hline Koga et al. (2000) [19] & $\mathrm{CT}$ & $0 / 11$ & $1 / 2$ & - & $10 / 10$ & $12 / 12$ & 35 \\
\hline Curry et al. (2000) [27] & CT & $0 / 4$ & $0 / 11$ & - & $29 / 49$ & $18 / 18$ & 82 \\
\hline Limb et al. (2002) [28] & CT & - & $3 / 28$ & - & $8 / 29$ & - & 57 \\
\hline $\begin{array}{l}\text { Overall number } \\
\text { Malignant vs. benign }\end{array}$ & & $1 / 48$ & $11 / 77$ & - & $75 / 146$ & $83 / 91$ & 362 \\
\hline Incidence of malignancy ( $\%)$ & & $2 \%$ & $14 \%$ & - & $51 \%$ & $91 \%$ & \\
\hline References & Modality & $\mathrm{BI}$ & BII & BIIF $^{\#}$ & BIII & BIV & Total \\
\hline \multicolumn{8}{|l|}{ After introduction of BIIF } \\
\hline Isreal et al. (2003) [29] & $\mathrm{CT}$ & - & - & - & $9 / 21$ & $16 / 16$ & 37 \\
\hline Isreal et al. (2003) [6] & CT & - & - & $7 / 42$ & - & - & 42 \\
\hline Harisinghani et al. (2003) [30] & $\mathrm{CT}$ & - & - & - & $17 / 28$ & - & 28 \\
\hline Isreal et al. (2004) [31] & $\mathrm{CT}$ and MRI & - & - & - & $14 / 14$ & $6 / 6$ & 20 \\
\hline Spaliviero et al. (2005) [7] & $\mathrm{CT}$ & & $2 / 9$ & $1 / 4$ & $6 / 12$ & $19 / 21$ & 46 \\
\hline Quaia et al. (2008) [8] & $\mathrm{CT}$ and CEUS & - & $0 / 3$ & $0 / 6$ & $5 / 13$ & $18 / 18$ & 40 \\
\hline O’Malley (2009) [9] & $\mathrm{CT}$ & - & - & $5 / 74$ & $27 / 33$ & & 107 \\
\hline Gahr et al. $(2009)^{*}[10]$ & $\mathrm{CT}$ & - & - & $7 / 50$ & - & - & 50 \\
\hline Song et al. (2009) [11] & $\mathrm{CT}$ & - & $3 / 26$ & $0 / 3$ & $21 / 38$ & $32 / 37$ & 104 \\
\hline Peng et al. (2010) [4] & CT and CEUS & $0 / 2$ & $0 / 3$ & - & $5 / 6$ & $12 / 13$ & 24 \\
\hline Kim et al. (2010) [12] & $\mathrm{CT}$ & $0 / 34$ & $3 / 22$ & $3 / 10$ & $19 / 26$ & $28 / 33$ & 125 \\
\hline Weibl et al. (2011) [22] & CT and MRI & - & $0 / 2$ & $2 / 3$ & $15 / 27$ & $30 / 39$ & 71 \\
\hline Pinheiro et al. (2011) [20] & $\mathrm{CT}$ & & & & $5 / 15$ & $19 / 22$ & 37 \\
\hline You et al. (2011) [32] & $\mathrm{CT}$ & - & - & - & $22 / 39$ & $31 / 36$ & 75 \\
\hline Our study & CT & - & - & $2 / 38$ & - & - & 38 \\
\hline $\begin{array}{l}\text { Overall number } \\
\text { Malignant vs. benign }\end{array}$ & & $0 / 36$ & $8 / 65$ & $27 / 230$ & $165 / 272$ & $211 / 241$ & 844 \\
\hline Incidence of malignancy (\%) & & $0 \%$ & $12 \%$ & $12 \%$ & $61 \%$ & $88 \%$ & \\
\hline
\end{tabular}

*BII and BIIF lesions were pooled

${ }^{\#}$ BIIF cysts that progressed and histologically were verified as malignant

upgrade lesions, probably because of the superior contrast resolution compared to $\mathrm{CT}$. The literature is still unequivocal on whether the higher contrast resolution of MR and CEUS will result in earlier detection of potential malignant lesions or inappropriate higher false-positive rates. Further research regarding the role of MR and CEUS are needed and forthcoming.

\section{Follow-up imaging for BIIF lesions}

Recommended follow-up protocols for BIIF cystic lesions vary in the literature. To detect potential progression, a multiphase contrast CT is needed. M.A. Bosniak proposed the first control CT to be done after half a year, and if the lesion was unchanged, a control CT should be repeated annually for a minimum of 5 years [6]. Other authors recommend close monitoring in the first year with CT scans after 3, 6 and 12 months. At our institution patients with complex Bosniak IIF cysts used to be followed according to the latter protocol and in cases without progression annually for 5 years. It should, however, be noted that very narrow follow-up periods may reduce detection rates if the changes in the cysts from examination to examination are very small. As a consequence of these considerations and the results of this study, we have dropped the early 3-month follow-up. However, due to the lack of prospective series, the most appropriate follow-up regimen in these patients is still debatable [9]. 
Bosniak IIF lesions vary in appearance: (1) BIIF lesions with minimal findings close to category II in complexity and (2) BIIF lesions that are closer to category III in complexity. M.A. Bosniak has recently suggested that BIIF cysts with minimal findings only need follow-up for 1-2-years, whereas more complex BIIF cysts should be followed for a longer period (e.g., 3-4 years or longer) [1]. This seems to be a reasonable compromise taking into consideration the high, cumulated radiation dose of repeated examinations. CT is still considered the gold standard when categorising complex renal cystic masses. For BIIF lesions an early switch to MRI/CEUS with a baseline examination immediately following the CT examination is now used at many institutions. Long-term data on such a regime may change clinical management in the future. Caution must be made for lesions $\leq 2 \mathrm{~cm}$ [1]. We have chosen to stop follow-up if no progression is seen after 5 years, suggesting that the BIIF lesion was benign. To our knowledge this has only been debated very sparsely in the literature, and studies on the most appropriate follow-up regimen in these patients are, as mentioned, warranted [1, 2, 5, 47].

\section{Biopsy and minimally invasive intervention}

Biopsy of moderate complex cystic masses in the kidney has recently come into focus and the trend seems to be a more aggressive approach $[2,9,15,30,48,49]$. This is presumably to avoid follow-up imaging of those BIIF lesions that are close to BIII and undoubtedly due to the possibility of using local nephron-sparing treatment (ablation with cryo/radiofrequency therapy and/or laparoscopic resection). Whether biopsy and aspiration of the cyst fluid should be used routinely is controversial. It may be problematic to accept a negative biopsy result since the renal cysts usually are very inhomogeneous. In general, it is recommended that Bosniak category III and IV lesions be treated surgically or with minimally invasive ablation measures. The treatment strategy depends on the size and localisation of the lesion and the patient's general condition. It should be noted, however, that the indication for minimally invasive treatment in cases with suspected malignancy is still regarded as being in the exploratory phase. Routine use of these minimally invasive methods should therefore be protocolised and results published.

Although our numbers are small, the data seem to be consistent in the regard that if progression occurs radiologically, it corresponds to pathological results. The corresponding aggressiveness of the lesions needs further evaluation in prospective studies, however. Our cases were analysed in consensus, so interobserver variability could not be evaluated. Like M.A. Bosniak, we believe that, if the complexity of a category II lesion is in question, the lesion should be placed in category IIF. In cases of disagreement among the radiologists, the lesion should always be placed in the highest category [5,
13, 47, 50]. Furthermore, decisions on the intervention may be easily influenced by clinical parameters, as in our series, in which surgical resection was omitted because of co-morbidity. Other comparable studies have the same limitation with regard to accordance between radiological and pathological progression, since not all category IIF lesions that progressed were resected $[6,9,10]$.

\section{Conclusion}

By critically evaluating the outcome of complex renal cysts using the Bosniak classification, we found that out of 32 Bosniak category IIF lesions only 5 (16\%) were upgraded during follow-up. Malignant progression did occur in two of these lesions, and follow-up examinations are considered necessary. The introduction of Bosniak category IIF seems promising, potentially resulting in a rational and an overall nephron-sparing approach to complex renal cysts.

Conflict of interest The authors declare no conflicts of interest. No funding has been received for this work. Data from this study were presented at ESUR 2011 in Dubrovnik, Croatia.

Open Access This article is distributed under the terms of the Creative Commons Attribution License which permits any use, distribution, and reproduction in any medium, provided the original author(s) and the source are credited.

\section{References}

1. Bosniak MA (2012) The Bosniak Renal Cyst Classification: 25 years later. Radiology 262(3):781-785

2. Graumann O, Osther SS, Osther PJS (2011) Characterization of complex renal cysts: a critical evaluation of the Bosniak classification. Scand J Urol Nephrol 45(2):84-90

3. Siegel CL, Mcfarland EG, Brink JA, Fisher AJ, Humphrey P, Heiken JP (1997) CT of cystic renal masses: analysis of diagnostic performance and interobserver Variation. AJR Am J Roentgenol 169:813-818

4. Peng Y, Jia L, Sun N, Li J, Fu L, Zeng J et al (2010) Assessment of cystic renal masses in children: comparison of multislice computed tomography and ultrasound imaging using the Bosniak classification system. Eur J Radiol 75(3):287-292

5. Israel GM, Bosniak MA (2005) An update of the Bosniak renal cyst classification system. Urology 66(3):484-488

6. Israel GM, Bosniak M (2003) Follow-up CT of moderately complex cystic lesions of the kidney (Bosniak category IIF). AJR Am J Roentgenol 181(3):627-633

7. Spaliviero M, Herts BR, Magi-Galluzzi C, Xu M, Desai M, Kaouk J, Tucker K, Steinberg APG (2005) Laparoscopic partial nephrectomy for cystic masses. J Urol 714:614-619

8. Quaia E, Bertolotto M, Cioffi V, Rossi A, Baratella E, Pizzolato R et al (2008) Comparison of contrast-enhanced sonography with unenhanced sonography and contrast-enhanced $\mathrm{CT}$ in the diagnosis of malignancy in complex cystic renal masses. AJR Am J Roentgenol 191(4):1239-1249 
9. O’Malley RL, Godoy G, Hecht EM, Stifelman MD, Taneja SS (2009) Bosniak category IIF designation and surgery for complex renal cysts. J Urol 182(3):1091-1095

10. Gabr AH, Gdor Y, Roberts WW, Wolf JS (2009) Radiographic surveillance of minimally and moderately complex renal cysts. BJU Int 103(8):1116-1119

11. Song C, Min GE, Song K, Kim JK, Hong B, Kim C-S et al (2009) Differential diagnosis of complex cystic renal mass using multiphase computerized tomography. J Urol 181(6):2446-2450

12. Kim DY, Kim JK, Min G-E, Ahn H-J, Cho K-S (2010) Malignant renal cysts: diagnostic performance and strong predictors at MDCT. Acta Radiol 51(5):590-598

13. Weibl P, Klatte T, Kollarik B, Waldert M, Schüller G, Geryk B et al (2011) Interpersonal variability and present diagnostic dilemmas in Bosniak classification system. Scand J Urol Nephrol 45(4):239244

14. Bosniak M (1991) Difficulties in classifying cystic lesion of the kidney. Urol Radiol 13:91-93

15. Lang EK, Macchia RJ, Gayle B, Richter F, Watson R, Thomas R et al (2002) CT-guided biopsy of indeterminate renal cystic masses (Bosniak 3 and 2F): accuracy and impact on clinical management. Eur Radiol 12(10):2518-2524

16. Bosniak A (1997) Diagnosis and management of patients with complicated cystic lesions of the kidney. AJR Am J Roentgenol 169:819-821

17. Cloix P, Martin X, Pangaud C, Maréchal JM, Bouvier R, Barat D et al (1996) Surgical management of complex renal cysts: a series of 32 cases. J Urol 156(1):28-30

18. Corica F, Iczkowski K, Cheng L, Zincke H, Blute ML, Wendel A et al (1999) Cystic renal cell carcinoma is cured by resection: a study of 24 cases with long-term followup. J Urol 161(2):408-411

19. Koga S, Nishikido M, Hayashi T, Matsuya F, Saito Y, Kanetake H (2000) Outcome of surgery in cystic renal cell carcinoma. Urology 56(1):67-70

20. Pinheiro T, Sepulveda F, Natalin RH, Metrebian E, Medina R, Goldman SM et al (2011) Is it safe and effective to treat complex renal cysts by the laparoscopic approach? J Endourol 25(3):471-476

21. Sahni VA, Mortele KJ, Glickman J, Silverman SG (2010) Mixed epithelial and stromal tumour of the kidney: imaging features. BJU Int 105(7):932-939

22. Weibl P, Klatte T, Kollarik B, Waldert M, Schüller G, Geryk B, et al. (2011) Interpersonal variability and present diagnostic dilemmas in Bosniak classification system. Scand J Urol Nephrol 45(4):239-244

23. Brown WC, Amis ES Jr, Kaplan SA, Blaivas JGAS (1989) Renal cystic lessions: predictive value of preoperative computerized tomography. J Urol 141:426A

24. Aronson S, Frazier HA, Baluch JD, Hartman DS, Christenson PJ (1991) Cystic renal masses: usefulness of the Bosniak classification. Urol Radiol 90:83-90

25. Wilson TE, Doelle E, Cohan RH, Wojno K, Korobkin M (1996) Cystic renal masses: a reevaluation of the usefulness of the Bosniak classification system. Acad Radiol 3(7):564-570

26. Bielsa GO, Arango TO, Cortadellas AR, Castro SR, Griñó Garreta J, Gelabert-Mas A (1999) The preoperative diagnosis of complex renal cystic masses. Arch Esp Urol 52:19-25

27. Curry NS, Cochran ST, Bissada NK (2000) Cystic renal masses: accurate renal CT. AJR Am J Roentgenol 175:339-342

28. Limb J, Santiago L, Kaswick JBG (2002) Laparoscopic evaluation of indeterminate renal cysts: long-term follow-up. J Endourol 16(2):7982

29. Israel GM, Bosniak M (2003) Calcification in cystic renal masses: is it important in diagnosis? Radiology 226(1):47-52

30. Harisinghani MG, Maher MM, Gervais D, McGovern F, Hahn P, Jhaveri $\mathrm{K}$ et al (2003) Incidence of malignancy in complex cystic renal masses (Bosniak category III): should imaging-guided biopsy precede surgery? AJR Am J Roentgenol 180(3):755
31. Israel GM, Hindman N, Bosniak M (2004) Evaluation of cystic renal masses: comparison of $\mathrm{CT}$ and $\mathrm{MR}$ imaging by using the Bosniak classification system. Radiology 231(2):365-371

32. You D, Shim M, Jeong IG, Song C, Kim JK, Ro JY et al (2011) Multilocular cystic renal cell carcinoma: clinicopathological features and preoperative prediction using multiphase computed tomography. BJU Int 108(9):1444-1449

33. Bird VG, Kanagarajah P, Morillo G, Caruso DJ, Ayyathurai R, Leveillee R et al (2010) Differentiation of oncocytoma and renal cell carcinoma in small renal masses $(<4 \mathrm{~cm})$ : the role of 4-phase computerized tomography. World J Urol 29(6):787-792

34. Jung DC, Oh YT, Kim MDPM (2012) Dual-source dual-energy CT evaluation of complex cystic renal masses. AJR Am J Roentgenol 199(6):1316-1319

35. Ascenti G, Mazziotti S, Mileto A, Racchiusa S, Donato R, Settineri NGM (2012) Utility of iodine overlay technique and virtual unenhanced images for the characterization of renal masses by dual-energy CT. AJR Am J Roentgenol 199(5):1026-1034

36. Little MP, Wakeford R, Tawn EJ, Bouffler SD, De Gonzalez AB (2009) Risks associated with low doses and low dose rates of ionizing radiation: why linearity may be (almost) the best we can do 1. Radiology 251(1):6-12

37. Brenner DJ, Hall EJ (2007) Computed tomography—an increasing source of radiation exposure. N Engl J Med 357:2277-2284

38. Tubiana $\mathrm{M}$ et al (2008) Computed tomography and radiation exposure - to the editor. N Engl J Med 358(8):850-853

39. BerringtondeGonzález A, Mahesh M, Kim K-P, Bhargavan M, Lewis R, Mettler F et al (2009) Projected cancer risks from computed tomographic scans performed in the United States in 2007. Arch Intern Med 169(22):2071-2077

40. Cem Balci N, Semelka RC, Patt RH, Dubois D, Freeman JA, GomezCaminero A et al (1999) Complex renal cysts: findings on MR imaging. AJR Am J Roentgenol 172:1495-1500

41. Shahzad K, Simms MS, Byass O (2011) Evaluation of contrast enhanced ultrasound for investigation of complex cystic renal masses. BJMSU 4(6):253-258

42. Piscaglia F, Nolsøe C, Dietrich CF, Cosgrove DO, Gilja OH, Bachmann Nielsen $M$ et al (2012) The EFSUMB Guidelines and Recommendations on the Clinical Practice of Contrast Enhanced Ultrasound (CEUS): update 2011 on non-hepatic applications. Ultraschall Med 33(1):33-59

43. Ignee A, Straub B, Brix D, Schuessler G, Ott M, Dietrich CF (2010) The value of contrast enhanced ultrasound (CEUS) in the characterisation of patients with renal masses. Clin Hemorheol Microcirc 46(4):275-290

44. Clevert D, Minaifar N, Weckbach S, Jung EM, Stock K, Reiser M (2008) Multislice computed tomography versus contrast-enhanced ultrasound in evaluation of complex cystic renal masses using the Bosniak classification system. Clin Hemorheol Microcirc 39:171-178

45. Ascenti G, Mazziotti S, Zimbaro G, Settineri N, Magno C, Melloni D (2007) Complex cystic renal masses: characterization with contrast-enhanced US. Radiology 243(1):158-165

46. Park BK, Kim B, Kim SH, Ko K, Lee HM, Choi HY (2007) Assessment of cystic renal masses based on Bosniak classification: comparison of CT and contrast-enhanced US. Eur J Radiol 61(2):310-314

47. Warren KS, McFarlane J (2005) The Bosniak classification of renal cystic masses. BJU Int 95(7):939-942

48. Agarwal MM, Hemal AK (2011) Surgical management of renal cystic disease. Curr Urol Rep 12(1):3-10

49. Park BK, Kim CK, Lee HM (2008) Image-guided radiofrequency ablation of Bosniak category III or IV cystic renal tumors: initial clinical experience. Eur Radiol 18(7):1519-1525

50. Park BK, Kim CK, Kim EY (2010) Differentiation of Bosniak categories IIF and III cystic masses: what radiologists should know. J Comput Assist Tomogr 34(6):847-854 